\title{
Libreros y editores foráneos a finales del siglo XVI: huellas francesas en la introducción de los novellieri en Castilla
}

\section{Leonardo Coppola \\ Università degli Studi “G. d'Annunzio” di Chieti-Pescara}

Título: Libreros y editores foráneos a finales del siglo XVI: huellas francesas en la introducción de los novellieri en Castilla.

Resumen: A finales del siglo XVI y principios del XVII, impresores y editores galos, que ya habían apostado en Francia por la traducción/comercialización de los novellieri, abren un nuevo camino literario en España, afirmándose como verdaderos "patrocinadores" del género importado de Italia. Este trabajo revela el importante papel que desempeñaron los libreros franceses no solo en la introducción de los novellieri, sino también en su provecho y éxito comercial en el panorama español, que también parece haber incorporado las estrategias comerciales del país vecino. Una atención particular se reserva a la traducción castellana de Le Piacevoli notti de Straparola.

Palabras clave: Novelle, Libreros, Novellieri, Editores, Straparola

Fecha de recepción: 20/5/2018.

Fecha de aceptación: 5/6/2018.
Title: Foreign Booksellers and Publishers at the End of the Sixteenth Century: French Trace in the Introduction of the novellieri in Castilla.

Abstract: At the end of the late sixteenth and early seventeenth centuries, Gallic printers and publishers, who already bet in France in the translation/commercialisation of the novellieri, open a new Spanish literary path, affirming themselves as true "sponsors" of the genre imported from Italy. The paper tries to demonstrate the important role that French booksellers had not only in the introduction of novellieri, but also in the profit and commercial success that these texts brought in the Spanish literary scene, which also enjoyed the possible commercial strategies coming from the French. Particular attention is given to the specific case of the Castilian translation of Straparola's Le Piacevoli notti.

Key words: Novelle, Booksellers, Novellieri, Publishers, Straparola

Date of Receipt: 20/5/2018.

Date of Approval: 5/6/2018. 
A la hora de bosquejar la tradición del Honesto y agradable entretenimiento de damas y galanes ${ }^{1}$ se pronosticaba cómo la historia editorial de la traducción española de Le Piacevoli notti de Giovan Francesco Straparola — primer hito de la novela corta espańola del siglo XVII ${ }^{2}$ - esta-

1 Un estudio pormenorizado sobre los asuntos editoriales de la obra puede leerse en Leonardo Coppola, "La proyección de Straparola en la novela española del Siglo de Oro”, Edad de Oro, XXXIII (2014), pp. 69-85; y Giovan Francesco Straparola, Honesto y agradable entretenimiento de damas y galanes (trad. Francisco Truchado), ed. Leonardo Coppola, Madrid, SIAL, 2016, pp. 23-44.

2 Sobre las traducciones de novellieri son imprescindibles los trabajos de Jean-Michel Laspéras, La nouvelle en Espagne au Siècle d'Or, Montpellier, Editions de Castillet, 1987; David González Ramírez, "En el origen de la novela corta del Siglo de Oro: los novellieri en España”, Arbor: Ciencia, pensamiento y cultura, 752 (2011), pp. 12211243; Guillermo Carrascón, "Apuntes para un estudio de la presencia de Bandello en la novela corta del siglo XVII", Edad de Oro, XXXIII (2014), pp. 53-67, y “Oneste o ejemplares. Bandello y Cervantes", Artifara, 13 bis (2014), pp. 285-305; y Iole Scamuzzi, "Honesto y rentable entretenimiento: restitutio de una buena inversión en la cultura”, en Hispanismos del mundo: diálogos y debates en ( $y$ desde) el Sur, ed. Leonardo Funes, Buenos Aires, Miño y Dávila, 2016, pp. 355-364. Para un análisis de los paratextos y la huella de los novellieri en la tradición española, véanse David González Ramírez, "En el origen de la novela corta del Siglo de Oro: los novellieri desde sus paratextos", Arbor: Ciencia, pensamiento y cultura, 756 (2012), pp. 813-828; Marcial Rubio Árquez, "Los novellieri en las Novelas ejemplares de Cervantes: la ejemplaridad", Artifara. Revista de lenguas y literaturas ibéricas y latinoamericanas, 14 (2013), pp. 33-58, "Lucas Gaitán de Vozmediano, Giraldo Cinzio y los inicios de la novella en España", Lejana. Revista crítica de narrativa breve, 7, 12 (2014), pp. 12; y, del mismo autor, "Los novellieri en Mateo Alemán: las novelas en el Guzmán de Alfarache (15991604)", en I novellieri italiani e la loro presenza nella cultura europea: rizomi e palinsesti rinascimentali, eds. Guillermo Carrascón y Chiara Simbolotti, Torino, Accademia University Press, 2015, pp. 633-645, "La novella en Cervantes: entre Alemán e Italia.", Anuario de Estudios Cervantinos, 12 (2016), pp. 297-309, "Mateo Alemán novelliere", eHumanista, 34 (2016), pp. 44-56 y "Sobre el difícil arte de intercalar novelle: Alemán y Cervantes", en Trayectorias literarias hispánicas: redes, irradiaciones y confluencias, ed. M. Rosso et al., Roma, AISPI edizioni, 2018, pp. 245-254. Véanse finalmente Marco Federici, "Cervantes y los novellieri: algunos ejemplos". AnMal, 36, 1-2 (2014), pp. 145-161, e Isabel Muguruza Roca, "Las traducciones de los novellieri en las Novelas ejemplares: Cervantes frente a Bandello y la negación del modelo italiano" en Traduzioni, riscritture, ibridazioni: Prosa e teatro fra Italia, Spagna e Portogallo, eds. Michela Graziani y Salomé Vuelta García, Firenze, Leo S.Olschki, 2016, pp. 91-102. 
ba sellada, al menos desde sus primeras apariciones, por libreros que, de cualquier modo, trababan estrechas relaciones comerciales con Francia. Ya en un trabajo previo $^{3}$ dimos a conocer una primera relación entre Pedro de Ibarra y Juan Ruelle, editores de la princeps aragonesa de la primera parte (1578) y de su reimpresión bilbaína (1580), respectivamente. Sin embargo, el origen francés del Honesto y agradable entretenimiento de damas y galanes también se percibe en sus impresores. En efecto, Matías Marés, el impresor de la reedición vasca, y René Rabut, tipógrafo de la edición granadina $(1582 / 83)$ de la primera parte, siguen remarcando en la traducción un matiz que procedía del otro lado de los Pirineos. Ahora bien, la tradición del «Straparola hispano», como procuraremos aclarar en estas páginas, parece haber seguido un particular recorrido, pasando antes por las manos de editores galos que habían apostado previamente por la divulgación de las traducciones de los novellieri para después, una vez comprobado su triunfo, llegar a la Península Ibérica. El ingreso de Straparola en la piel de toro y la consiguiente divulgación de los novellieri parece, por lo tanto, estar marcada por una constante: la huella francesa ${ }^{4}$.

Para arrojar luz sobre la antedicha influencia gala en la traducción del baezano Francisco Truchado tendremos que movernos primero por el taller aragonés de Juan Soler — donde vio la luz la supuesta princeps de la primera parte costeada por Pedro de Ibarra en $1578^{5}$ - y también por el

3 Leonardo Coppola, "La proyección de Straparola".

4 A modo de ilustración, en el apéndice se ofrecen un par de cuadros sobre los editores e impresores de la tradición del Honesto y agradable entretenimiento de damas y galanes.

5 El texto, exhumado al unísono por David González Ramírez, "La princeps del Honesto y agradable entretenimiento de damas y galanes (Zaragoza, 1578) de Straparola: hallazgo de una edición perdida", AnMal, 34, 2 (2011), pp. 517-528, y Leonardo Coppola, "Prolegómenos a la edición del Honesto y agradable entretenimiento de damas y galanes", en Pictavia aurea. Actas del IX Congreso de la Asociación Internacional Siglo de Oro, eds. Alain Bègue y Emma Herrán Alonso, Toulouse, Presses Universitaires du Mirail, pp. 367-374, ya lo registraba Gerónimo Borao y Clemente, La imprenta en Zaragoza con noticias preliminares sobre la imprenta en general, Zaragoza, Imprenta de Vicente Andrés, Cuchillería, 42, 1860, p. 45. Sobre la actividad editorial de Soler, véase Juan Manuel Sánchez, Bibliografía aragonesa del siglo XVI, II, Madrid, Imprenta clásica española, 1914, p. 9, y Juan Delgado Casado, Diccionario de Impresores españoles (siglos XV-XVII), Madrid, Arco, 1996, p. 656. Un panorama detallado sobre la producción tipográfica y las relaciones de Soler con los libreros, 
bilbaíno de Matías Marés, en el que Juan Ruelle volvería a darla a los tórculos en 1580. Dada la reconocida importancia en la historia del libro del trabajo de los editores ${ }^{6}$, como reconocen Péligry ${ }^{7}$ y Rojo Vega $^{8}$, nuestra atención se concentrará en esa categoría.

Así, el librero de la princeps aragonesa del Honesto y agradable entretenimiento de damas y galanes, Pierre Collet, que, en conformidad con la costumbre de adaptar los apelativos a la lengua local, solía firmar en las portadas como Pedro de Ibarra o Pedro Colé de Ybarra, era originario de La Champagne9. De Amberes, en cambio, según opinan Ronco ${ }^{10}$ y Alonso Álvarez ${ }^{11}$, procedía Matías Marés. Además de compartir nacionalidad extranjera, como ratificara Rodríguez Pelaz ${ }^{12}$, el uno (Ibarra) fue sucesor de la tipografía del otro (Marés) ${ }^{13}$. No en vano, según constata Odriozola $^{14}$, en aquellos ańos eran dos "los impresores que trabajan en Bilbao: Matías Mares y Pedro Colé de Ibarra”. Más allá de sus orígenes,

entre los cuales también se cuenta Pedro de Ibarra, pero sin remitir a nuestra traducción, lo perfila Ángel San Vicente, Apuntes sobre libreros, impresores y libros localizados en Zaragoza entre 1545 y 1599, Zaragoza, Gobierno de Aragón, Departamento de Cultura y Turismo, 2003, pp. 212-219.

6 A propósito del papel de los editores, véase Manuel José Pedraza García, El libro español del Renacimiento: la "vida" del libro en las fuentes documentales contemporáneas, Madrid, Arco Libros, 2008.

7 Charles Péligry, "Les éditeurs lyonnais et le marché espagnol aux XVIe et XVII siècles", en Actes du Colloque de la Casa de Velázquez: Livre et lecture en Espagne et en France sous l'Ancien Régime, Madrid, Casa de Velázquez, 1981, pp. 85-93.

8 Anastasio Rojo Vega, "El negocio del libro en Medina del Campo. Siglos XVI y XVII", Investigaciones históricas: Época moderna y contemporánea, 7 (1987), pp. 17-26 (p. 19).

9 Celia Rodríguez Pelaz, "El grabado barroco en los impresos vasco-navarros", Ondare, 19 (2000), pp. 151-182 (p. 179).

10 Milagros Ronco, "Primer siglo de la imprenta en Vizcaya", Revista General de Información y Documentación, 7, 2 (1997), pp. 359-364 (p. 359).

11 Óscar Alonso Álvarez, “Mathias Mares: un impresor en la villa”, Bilbao, 209 (2006), p. 39.

12 Celia Rodríguez Pelaz, op. cit., pp. 178-179.

13 También Juan Delgado Casado, op. cit., pp. 148-149 y 468-469, el cual nos informa de su instancia bilbaína (1588-1610?), reconoce al impresor francés, que a veces se firmaba Pedro de Ibarra, como sucesor de Marés.

14 Antonio Odriozola, "Nota bibliográfica sobre los libros impresos en Bilbao por Matías Mares", RIEV: Revista internacional de los estudios vascos, 25 (1934), pp. 1-49 (p. 2). 
se nos aclara cómo, en realidad, la actividad de Ibarra no se limitará a la de librero en Zaragoza, como exhaustivamente reconoce González Ramírez ${ }^{15}$, sino que se perpetuaba en Bilbao, donde ejerció como impresor tras el abandono de Marés ${ }^{16}$.

Antes de pasar revista a los textos salidos de las prensas de Ibarra, convendrá echar ya un vistazo al revelador camino profesional de Marés. Como la mayoría de los extranjeros asentados en territorio vasconavarro ${ }^{17}$, también el tipógrafo flamenco de la reimpresión del Honesto y agradable entretenimiento de damas y galanes era un punto itinerante. En buena lógica, tras suprimir el acento del apellido para ocultar sus orígenes forasteros ${ }^{18}$, dicho tipógrafo — que dejaría constancia de su actividad en otras ciudades de España (Salamanca, Logroño ${ }^{19}$, Santo Domingo de la Calzada, Pamplona e Irache $)^{20}$ — se afincó en Bilbao entre 1577 y 1578 . Junto a la traducción de Straparola, allí se imprimieron hasta 1587 los libros que nos interesan: el De gloria et De Nobilitate civili et christiana (1578), de Jerónimo Osorio; Examen de ingenios (1580), de Huarte de San Juan; El Patrañuelo (1580), de Juan de Timoneda; el Libro del invencible caballero Primaleón (1585), Horas de recreación (1586), de Ludovico Guicciardini ${ }^{21}$, y El Caballero Asisio (1587), de

15 David González Ramírez, "La princeps del Honesto y agradable", pp. 525-526.

16 A propósito de la nutrida producción de textos financiados por Ibarra, véanse también los catálogos de Juan Manuel Sánchez, Impresores y libros impresos en Aragón en el siglo XVI, Madrid, Imprenta alemana, 1908; José Simón Díaz, Bibliografía de la Literatura Hispánica, V-VI, Madrid, CSIC, 1973; y Alexander Wilkinson, Libros Ibéricos: Libros publicados en español o portugués o en la Península Ibérica antes de 1601, Leiden, Brill, 2010.

17 Julio César Santoyo, "La imprenta en el País Vasco: breve panorama histórico", en I Seminario sobre Patrimonio Bibliográfico Vasco, Gasteiz, Eusko Jaurlaritza, 2005, pp. 109-123 (p. 109).

18 Milagros Ronco, op. cit., p. 361, y Óscar Alonso Álvarez, op. cit., p. 39.

19 Sobre la actividad logrońesa remitimos a José Lope Toledo, "La imprenta en La Rioja”, Berceo, LVI (1960), pp. 313-330, Julián Tomás Bravo Vega, "Imprenta e impresores en la Rioja durante los siglos XVI y XVII: la imprenta de Juan de Mongastón Fox”, Berceo, 122 (1992), pp. 53-59; y María Marsá Vilá, La imprenta en La Rioja (siglos XVI-XVII), Madrid, Arco, 2002, pp. 46-50.

20 Juan Delgado Casado, op. cit., p. 419.

21 Véase ahora Lodovico Guicciardini, Horas de recreación, trad. Vicente Millis, ed. crítica Iole Scamuzzi, Madrid, Sial, 2018. 
Gabriel Mata (Delgado Casado, 1996: 420-421 y Ruiz Fidalgo, 1994: $92-93)^{22}$.

Así y todo, en 1588 Matías Mares pasaría a Logroño y ese mismo año Pedro Cole de Ibarra sentó reales en Bilbao ${ }^{23}$. Basándonos en el catálogo de José Julio de la Fuente ${ }^{24}$, Pedro de Ibarra dio a la estampa bilbaína un Romance (un pliego suelto en $4^{\circ}$ atribuido a Juan de Mongastón) sobre la inundación de la capital vasca ${ }^{25}$; Orden de bien casar, y avisos de casados, de Juan de Esteban (1595), y Doctrina Christiana en Romance y Bascuence, del doctor Ostolaza (1596) ${ }^{26}$. Como indiqué en otro trabajo ${ }^{27}$, la alianza Mares-Ibarra se documentaría — principalmente — a partir de la portada de la obra escrita por el bachiller Juan de Esteban. Se advierte, empero, la discordancia entre los datos editoriales de dicho frontispicio y del colofón. Mientras en el primero consta que el texto se imprimió "en casa de Cole de Ibarra 1595", en el segundo se lee: "en la oficina de Mathias Mares $1581 " 28$. A este propósito, Allende-Salazar ${ }^{29}$ convalida que Cole de Ibarra "solo rehízo la portada" de Mares. Para probarlo hay que abundar en las tiradas bilbaínas de Mares. De hecho, a la luz de las pesquisas de

22 Juan Delgado Casado, op. cit., pp. 420-421, y Lorenzo Ruiz Fidalgo, La imprenta en Salamanca (1501-1600), I, Madrid, Arco, 1994, pp. 92-93. Para una completa catalogación de las tiradas surgidas del taller bilbaíno, y no solo, véase Antonio Odriozola, op. cit. Más detalles sobre la imprenta vizcaína pueden hallarse también en Milagros Ronco, op. cit.

23 A propósito de los diferentes sucesores del taller bilbaíno, véase Milagros Ronco, $o p$. cit., pp. 363-364.

24 José Julio de la Fuente, Catálogo por orden alfabético de escritores vizcainos antiguos y modernos, de que tengo noticia, asi de los que han publicado sus obras como de aquellos cuyas producciones permanecen inéditas, Bilbao, 1871, p 99.

25 El espantoso y doloroso diluvio que en la villa de Bilbao ha sucedido con los demas pueblos comarcanos que a las orillas del rio estan fundados, en este año de 1593 a veynte $y$ dos dias de Setiembre que duro su impetu desde media noche de San matheo hasta medio dia que empezo a menguar, Bilbao, Pedro Ybarra, 1593. Cfr. Juan Delgado Casado op. cit. p. 468 y Alexander Wilkinson, op. cit., p. 516.

26 Ibidem, pp. 69 y 338.

27 Leonardo Coppola, "La proyección de Straparola".

28 José Julio de la Fuente, op. cit., p. 99.

29 Juan Allende-Salazar, "De Bibliografía. Notas para la historia de la imprenta en el País Vasco", en I Congreso de Estudios Vascos (Oñate, 1918), Bilbao, Bilbaína de Artes Gráficas, 1919-1920, pp. 644-671 (p. 666). 
Odrionzola ${ }^{30}$ y Ronco ${ }^{31}$, en 1581 Mares estampó también el Arte de bien casar, de Juan de Esteban. Y como se desprende de la reproducción de la portada de Odrionzola ${ }^{32}$, en ella figura a pie de página Pedro Cole de Ibarra. Queda razonado, entonces, que Cole de Ibarra solo entregó a los tórculos la portada —donde aparece con un título diferente: Orden de bien casar, y avisos de casados-, de modo que, como informa AllendeSalazar $^{33}$, el resto de la impresión resulta idéntica a la de Mares. Años después de la aparición de la primera edición de Mares, Cole de Ibarra pudo hacerse cargo de los ejemplares sobrantes, que se renovaron con una nueva portada con datos actualizados para favorecer su venta. Se trataría, en fin, de un caso de emisión "paratextual” de una misma edición que no afecta al texto.

Con todo, la presencia de Ibarra en la cubierta de la edición (1581) de Mares atestigua una colaboración previa a la mudanza de Ibarra al País Vasco (1588). Sea como fuere, la Summa de casos de consciencia, de Juan de Pedraza (Zaragoza, Juan Soler, 1578) — ausente en las listas de Delgado Casado ${ }^{34}$ y de Ronco ${ }^{35}$ — se nos antoja otro testimonio de cooperación, toda vez que se imprime, apenas un año más tarde, también en el taller vascuence de Mares $^{36}$. La obra se publica en la misma oficina de la princeps de la traducción de Truchado. Con todo, considerando su alianza con Soler, Ibarra bien pudo actuar como intermediario entre las tipografías y procurarle a Mares el texto de Pedraza. Tampoco excluyo, claro está, que lo mismo pudo ocurrir con la traducción de Straparola. Y a todo ello se suman otras pistas que confirmarían la colaboración «a dos prensas»: en 1609, Ibarra reedita las Ordenanzas municipales de Bilbao (Mares, 1579) ${ }^{37}$ y el segundo volumen del Caballero Asisio, cuya

30 Antonio Odriozola, op. cit., pp. 16-18 y 23.

31 Milagros Ronco, op. cit., p. 362.

32 Antonio Odriozola, op. cit., p. 23.

33 Juan Allende-Salazar, op. cit., p. 666.

34 Juan Delgado Casado op. cit.

35 Milagros Ronco, op. cit.

36 Alexander Wilkinson, op. cit., p. 564.

37 José Luis de Orella Unzué, "Las Ordenanzas Municipales de Orduña en el siglo XVI", en La Ciudad Hispánica durante los siglos XIII al XVI, I, Actas del Congreso celebrado en La Rábida, Madrid, Universidad Complutense, 1985, pp. 337-375 (p. 351, n. 56). 
primera parte (1587) sacó Mares en Bilbao antes de emigrar a Logroño en $1588^{38}$.

Prestaré atención ahora al editor de la reedición de 1580: Juan Ruelle. Lo dicho a propósito de Ibarra y Mares vale también aquí: "Al tratarse de nombres y apellidos extranjeros existe una enorme cantidad de variantes [...], dependiendo de cómo entendía cada escribano que debía escribirse" 39 . Es el caso de Juan Ruelle, o mejor, de la castellanización de Jean Ruelle o Ruellé. En efecto, se trata, a nuestro juicio, del mismo Jean Ruelle que aparece en las varias portadas de obras publicadas en Francia como "libraire demeurant rue sainct Jaques, à l'enseigne S. Hierosme" 40 .

Mientras las tiradas de Soler y Mares eran heterogéneas, no podemos decir lo mismo de sus libreros. Al margen del traslado de Straparola, Pedro de Ibarra había mostrado cierto interés por textos devocionales ${ }^{41}$; mientras que Jean Ruelle, como se deduce de las ediciones que financió, se inclinaba hacia obras pertenecientes a un modelo narrativo indiferenciado. No sorprende por ello que su nombre se afilie a títulos como Le Laberinthe d'amour, de Giovanni Boccaccio (Paris, Jean Ruelle, 1571); Les heures de récréation et après-disnées, de Ludovico Guicciardini (Paris, Jean Ruelle, 1571), Epistres des princes, de Girolamo Ruscelli (Paris, Jean Ruelle 1572) ${ }^{42}$ — las tres traducidas por François Belleforest—; La Circé (Paris, Jean Ruelle, 1572), traducción del homónimo texto de Giovan Battista Gelli, realizada por Denis Sauvage ${ }^{43}$, y Le Printemps, de Jacques

38 Juan Allende-Salazar, op. cit., p. 653.

39 Anastasio Rojo Vega, "El negocio del libro", p. 20, n. 9.

40 Ruelle (Jean II), hijo de Jean I y marido de Catherine Bourdin, nació el 8 de enero de 1541 (Philippe Renouard, Repertoire des imprimeurs parisiens libraires, fondeurs des caractères et correcteurs d'imprimerie: depuis l'introduction de l'Imprimerie a Paris (1470) jusqu'a la fin du seizième siècle, Paris, M. J. Minard, 1965, p. 386). Después de la muerte del padre en 1571, hereda su actividad tipográfica hasta 1606 (Philippe Renouard, Imprimeurs parisiens, libraires, fondeurs de caractères et correcteurs d'imprimerie, depuis l'introduction de l'imprimerie a Paris (1470) jusqu'a la fin du XVIe siècle, Cambridge, University Press, 2011, p. 334.

41 David González Ramírez, "La princeps del Honesto", p. 526.

42 Michel Simonin, Vivre de sa plume au XVIe siècle ou La Carrière de François de Belleforest, Genève, Droz, 1992, pp. 251 y 264.

43 Béatrice Drecq, Catalogue descriptif des éditions francaises, néolatines et autres 15011600 de la Bibliotheque municipale de Poitiers: un fonds renaissant, Genève, Slatkine, 2000, p. 302. 
d’Yver (Paris, Jean Ruelle, 1572) ${ }^{44}$. Cabe señalar, además, que de Le Printemps existieron ejemplares coeditados por Jean Ruelle y Abel L'Angelier, uno de los más grandes editores/impresores parisinos que, según veremos a continuación, dejará su huella en la historia editorial francesa de Le Piacevoli notti ${ }^{45}$.

En virtud de este panorama, acaso se entiendan algo mejor las pautas editoriales del librero L'Angelier. Por ser casi todas traducciones de novellieri - salvo Le Printemps d'Yver, que de todas maneras es una colección de novelle inspirada en Bandello, Boccaccio y Marguerite de Navarre-, sus ediciones muestran la predilección por tal género literario. El interés demostrado hacia obras afines a Le Piacevoli notti supone, a nuestro entender, que el hasta ahora llamado Jean Ruelle se correspondería con el mismo Juan Ruelle de la edición bilbaína.

Viajemos ahora hasta el mercado editorial español. Más allá de la traducción de Straparola a cargo de Truchado, el hispanizado Juan Ruelle se asocia una segunda vez al taller de Mares. El mismo año de publicación de la reedición bilbaína del Honesto y agradable entretenimiento de damas y galanes (1580), su nombre figura en la portada del Patrañuelo ${ }^{46}$, que, recordándonos a las obras editadas en Francia, no se aparta de la tendencia editorial

44 Jean Balsamo y Michel Simonin, Abel L'Angelier \& Françoise De Louvain, 15741620: Suivi Du Catalogue Des Ouvrages Publiés Par Abel L'Angelier, 1574-1610, et La Veuve L'Angelier, 1610-1620, Genève, Droz, 2002, p. 142. Véase la edición moderna: Jacques Yver, Le Printemps d'Yver, ed. Marie-Ange Maignan en collaboration avec Marie Madeleine Fontaine, Genève, Droz, 2015.

45 Otras obras editadas por Ruelle son: la Description philosophale (Paris, 1571), de Barthélemy Aneau (Jacques Brunet, Manuel du libraire et de l'amateur de livres, II, Paris, Libr. de Firmin Didot., 1861, 621); Le livre de la fontaine périlleuse, avec la chartre d'amours, autrement intitulé le songe du verger (Paris, 1572), de Jacques Gohory (Johann Georg Theodor Grässe, Trésor del livres rares et précieux: on Nouveao dictionnaire bibliografique, Supplement, IV, Dresde, Rudolf Kuntze, Libraire editeur, 1863, p. 236); Le miroir et institution du prince, contenant comme les grands se doivent comporter pour leur grandeur et pour le salut et repos de leurs subjects, de Jean Maugin (Paris, 1573) (Isidore Plaisant, Catalogue ou Description bibliographique raisonnée des livres de feu Pierre-Josep Baudewyns, I, Gent, P. J. De Mat, 1818, p. 99); y la Histoire du preux chevalier Palmerin d'Angleterre, des princes Florian du Désert et Florendos (Paris, 1574) (Jacques Detune, Catalogue des livres rares et précieux de la bibliothèque de feu m. Detune, Paris, Antoine-Augustin Renouard, 1806, p. 103.

46 Alexander Wilkinson, op. cit., p. 718. 
novelística de raigambre italiana seguida ya en París. Además de la probada colaboración entre Ruelle y Mares, como se infiere de la paráfrasis de las Piacevoli notti y del propio Patrañuelo, nótense ahora las correspondencias de algunas ediciones del "bilbaíno" con la producción parisina del mismo editor foráneo: las Horas de recreación (Bilbao, 1586), que Jean Ruelle ya había editado en París en 1571, y del Libro del invencible caballero Primaleón, hijo de Palmerín de Oliva (1585), que corresponde al segundo libro del Histoire du preux chevalier Palmerin d'Angleterre, publicado, de nuevo en la capital gala, en 1574. Ambos comparten, además, una publicación de Girolamo Ruscelli, que entre tantas cosas se encargó de clásicos como el Decamerón: mientras Matías Mares publicaba en Salamanca (1570) el Libro de los Secretos del reverendo Don Alexo Piamontes, traducción de Antonio de Fumo del Dé secreti del reverendo Donno Alessio Piemontese, dos ańos después Jean Ruelle editaría del mismo autor la traducción de las Lettere di principi (París, 1572), de François Belleforest. No cabe duda, entonces, de que también entre ellos hubo un asiduo apoyo editorial. También la Histoire du plus espouventable et admirable cas qui ait jamais esté ouy au monde (Paris, Jean Ruelle, 1574), de Guillaume de La Tayssonnière, respeta los mismos gustos narrativos presentes en la novella IX, 5 del Honesto y agradable entretenimiento, versión del Amore maligno, il cui fine fu pessimo: storia vera accaduta in Fiorenza, de Anton Francesco Doni ${ }^{47}$. El modelo del ajeno cuento de Straparola sigue el clásico repertorio de las "historias trágicas” de Bandello, muy

47 Ausente en el original italiano, ya Doris Senn, "Le Piacevoli notti (1550/53) von Giovan Francesco Straparola, ihre italienischen Editionen und die spanische Übersetzung Honesto y agradable Entretenimiento de Damas y Galanes (1569/81) von Francisco Truchado", Fabula, 34 (1993), pp. 45-65 (p. 50), señaló que se trataba de la traducción del Esempio della crudeltà usata da un marito ad una moglie. Storia vera accaduta a Firenze de Doni —opinión compartida en Leonardo Coppola, "Traducción y dispositio: Truchado y Le piacevoli notti”, Dicenda. Cuadernos de Filología Hispánica, XXX, I Anejo (2012), pp. 141-153 (p. 144) — sin anotar, empero, que además de publicarse en las Lettere de Doni (1543) y en el Raverta (1544) de Giuseppe Betussi, el mismo relato se hallaba en los Pistolotti amorosi (1552) de Doni, sin duda la fuente directa para la adición de Truchado, como señala Marco Federici ("La huella de Boccaccio en el Renacimiento espańol y la recepción de Le Piacevoli notti de Straparola", Dicenda. Cuadernos de Filología Hispánica, 32 (2014), pp. 95-111 (p. 100), "Un viaje de despedida: intromisiones en Le Piacevoli notti españolas", Dialogoi, rivista di studi comparatistici, II (2015), pp. 145-166, y Francisco Truchado, Honesto y agradable entretenimiento de damas y galanes, ed. Marco Federici, Roma, Nuova Cultura, 2014, p. 25). 
apreciadas por el público francés de aquel entonces. Sea como fuere, salta a la vista el mismo interés comercial que ambos perseguían. A raíz de todos estos datos, detrás de las preferencias tipográficas de Matías Mares se escondía seguramente el ánimo, la promoción y la planificación de Jean Ruelle.

Volviendo por un momento a lo dicho a propósito de Le Printemps d'Yver, se había dado ya a conocer la existencia de ejemplares coeditados por Jean Ruelle y Abel L'Angelier. Este particular reparto editorial se repetiría con las ediciones de la Histoire et chronique mémorable (París, 1574) y de Les Poesies (París, 1574) ${ }^{48}$. Pues bien, Abel L'Angelier, uno de los últimos y notables libreros de Palacio, ejerce en París la actividad de editor y tipógrafo desde 1569 a $1609^{49}$. Y su aparcería con Jean Ruelle no debiera caer en saco roto. De hecho, el nombre de Abel L'Angelier se vincula a distintas ediciones francas de Le Piacevoli notti, con las cuales el editor de la traducción castellana hubiera podido toparse en Bilbao sin dificultad. La redacción gala de Le Piacevoli notti, cuya primera parte corrió a cargo de Jean Louveau y fue editada por Guillaume Rouillé, desfilaría por primera vez en Lyon en 1560. Doce años después, Benoist Rigaud ${ }^{50}$ reedita en la misma ciudad una edición de bolsillo que llegó, justo al año siguiente, también a París, donde, solo la primera parte, se publicaría en el taller de Mathurin Martin ${ }^{51}$. La segunda parte aparece únicamente después de la versión de Pierre de Larivey. El traductor, champenois como Ibarra, cuenta entre sus trabajos el Second et dernier livre des Facetieuses nuicts, editado en París por L'Angelier, en 1576. Fruto de su éxito, al año siguiente el propio L'Angelier lo reeditaría, pero esta vez junto a la primera parte de Louveau (Lyon, Rouillé, 1560) ${ }^{52}$. Otras reediciones del mismo tipógrafo, muestra del enorme éxito cosechado, salieron en 1581 y 1585 ; las dos con ambas partes reunidas ${ }^{53}$.

48 Jean Balsamo y Michel Simonin, op. cit., pp. 143-144.

49 Ibidem, p. 15.

50 La Universidad de Barcelona custodia en la CRAI Biblioteca de Reserva (XVI1190) un ejemplar en $12^{\circ}$ de la reimpresión de la segunda parte realizada en Lyon (1572) por el mismo Benoit Rigaud.

51 Ruth Bottigheimer, "France’s First Fairy Tales: The Restoration and Rise Narratives of 'Les facetieuses nuictz du Seigneur François Straparole”, Marvels \& Tales, 19 (2005), pp. 17-31 (pp. 21-22).

52 Jean Balsamo y Michel Simonin, op. cit., pp. 146 y 149-150.

53 Para un cuadro detallado de las ediciones francesas de Le Piacevoli notti, véase Ruth Bottigheimer, op. cit., pp. 28-29. 
De acuerdo con la indiscutible colaboración entre Ruelle y L'Angelier, es probable, además, que este último tuviera relaciones con quien sufragó la edición aragonesa: Pierre Collet de Ibarra. A este propósito, el único indicio que hemos encontrado se cifra en un contrato nupcial del 26 de noviembre de 1602. El documento, además de aludir a un tal François Louvain, da noticia de la presencia de L’Angelier y Pierre Collet como testigos de a un matrimonio celebrado en París ${ }^{54}$. Más allá de la lejanía cronológica, la presencia de Collet, es decir, Pedro de Ibarra, en París acreditaría sus desplazamientos hacia rincón nativo, donde no excluyo que mantuviese relaciones comerciales con editores, entre los cuales podría figurar L'Angelier, el mismo que, no se olvide, publicó dos ediciones francesas de Le Piacevoli notti justo en los dos años (1576 y 1577) que antecedieron a su impresión zaragozana. A estas alturas, considero que el riesgo asumido por Ibarra (hasta entonces sugerido, sobre todo, por los textos devocionales) con su estampa aragonesa ${ }^{55}$ pudo ser incitado y hasta garantizado por Abel L'Angelier.

Detengámonos ahora en el tipógrafo de la edición bilbaína de la traducción de Straparola. Al lado de los castellanizados Pedro de Ibarra y Juan Ruelle, parece que también Matías Mares tuvo relaciones con el otro lado de los Pirineos; así lo revelarían al menos varias de sus mudanzas durante los años setenta. Tras haber ejercido en Salamanca (1566-1571), y antes de llegar a Bilbao, Mares prestó servicio en Burgos (1572-1577) a su connacional Francisco de la Presa ${ }^{56}$. En 1574 es enviado a París para la compra de moldes y luego a Nantes para reclutar mano de obra. De regreso de su viaje, y a su paso por Bilbao, centro neurálgico de comercio y actividades mercantiles, Delgado Casado ${ }^{57}$ reconoce que Mares hubiera podido empezar ya a reflexionar sobre su marcha a la capital vasca. De hecho, tras la muerte de la Presa, Juan, el hijo del tipógrafo, echó del taller a Mares, quien, finalmente, se trasladaría a Bilbao (1577-1587).

54 Jean Balsamo y Michel Simonin, op. cit., p. 470.

55 De ella se ha tratado en Leonardo Coppola, "La proyección de Straparola".

56 Cf. María Luz Basas Fernández, "Francisco de la Presa, hidalgo y mercader. Historia de un hombre de negocios del siglo XVI", Boletín de la Institución Fernán González, XI (1954), pp. 351-359.

57 Juan Delgado Casado, op. cit., p. 420. 
Según Delgado Casado ${ }^{58}$, uno de los motivos de su alejamiento del laboratorio burgués fue la escasa calidad y el excesivo número de erratas que presentaban sus libros. En efecto, los muchos errores que se registran en el testimonio bilbaíno del Honesto y agradable entretenimiento de damas $y$ galanes $^{59}$ confirmarían la escasa calidad advertida por los estudiosos $^{60}$.

Una vez asentada su oficina en las Vascongadas, no descato que entre los primeros mecenas de sus ediciones hubiera libreros relacionados con la comercialización editorial francesa. Aprobaría mis sospechas la inaugural tirada de su minerva: el De gloria et De Nobilitate civili et christiana, de Jerónimo Osorio (1578), costeado por "Petri Landri" ${ }^{61}$. Tras asociarse con conterráneos como fueron Pierre Landry, antes (1578), y Juan Ruelle, después (1580), Matías Mares reeditó en Bilbao el Examen de ingenios (1580) de Huarte de San Juan, cuya primera edición había salido, además, de las prensas baezanas de Juan Bautista de Montoya —impresor de la segunda parte del Honesto y agradable entretenimiento de damas y galanes_ en 1575. En 1578 aparecería su reimpresión en el taller pamplonica de Thomás Porralis —el mismo en el que se asentará Mares tras la muerte del hijo, Pedro ${ }^{62}$ - la que se utilizará como base para las siguientes ${ }^{63}$. Entre ellas destacan en 1580 la bilbaína de Mares y la traducción lionesa de Didier, que bien pudo recibir el texto directamente de nuestro tipógrafo ambulante o, fruto de las relaciones con Lyon, del editor Pierre Landry ${ }^{64}$.

\section{Ibidem.}

59 Cf. Giovan Francesco Straparola, op. cit.

60 Sobre los muchos errores tipográficos en el taller dirigido por Mares, remitimos a María Luz Basas Fernández, "Cuando, cómo y porqué vino a Bilbao el impresor Matías Mares", en La imprenta en Bilbao en el siglo XVI, ed. José Julio de la Fuente, Bilbao, Comisión Organizadora de la V Feria del Libro, 1972, pp. 121-123 (p. 122).

61 Pierre Landry, librero lionés que ejercía su actividad principalmente entre Medina del Campo y la ciudad gala, era una de las figuras más importantes en el comercio de libros entre Francia y España (Anastasio Rojo Vega, "El negocio del libro" en Impresores, libreros y papeleros en Medina del Campo y Valladolid en el siglo XVII, Valladolid, Consejería de Cultura y Turismo, 1994, pp. 41-45).

62 Julio César Santoyo, op. cit., p. 109.

63 José Luís de Orella Urzúe, op. cit., pp. 50-51.

64 De la edición bilbaína dependen también las tres flamencas: Leyden, J. Pats (1591); Amberes, "en la Oficina Plantiniana por Francisco Rafelengio" (1593), y, del mismo taller, la de 1603 [Guillermo Serés, "Huarte de San Juan, Juan", en Diccionario filológico de literatura española siglo XVI, ed. Pablo Jauralde Pou, Madrid, Editorial 
Pues bien, queda así probado, tal como sugerirían sobre todo sus primeros años en la villa vasca, y en Pamplona después, que Matías Mares trabó estrechas relaciones comerciales con el mundo francés y sus figuras asociadas a las imprentas, aspecto que nos induce a confirmar también los contactos con su sucesor, Pedro de Ibarra.

Como se ha indicado en otro lugar ${ }^{65}$, el origen francés de editores e impresores llevó, así, a una secuela editorial del texto de Straparola, como deja patente la reedición bilbaína. En suma, seducido por el éxito francés del novelista italiano, Juan Ruelle —que esperaba obtener el mismo éxito que L'Angelier - pudo convencer a Matías Mares para emprender el mismo camino editorial. Aprovechándose del triunfo de la novella y de la literatura lasciva en Francia ${ }^{66}$, al menos hasta 1580, Mares, alentado por su librero, pudo procurarse el texto de Ibarra, quizás igualmente sugestionado dos años antes por Abel L'Angelier y su fecundo proyecto straparoliano. En efecto, mi teoría quedaría refrendada, como razoné en mi edición del Honesto y agradable entretenimiento de damas y galanes $^{67}$, por la collatio que ratifica la filiación del texto bilbaíno con el aragonés, reconociendo, claro está, también las relaciones apuntadas en este trabajo.

Así, Ruelle - tras debutar en Francia con la edición de Les heures de recréation, de Ludovico Guicciardini (1571), reeditada en 1573 y 1576 acometió también en Espańa la venta de cuentistas y novellieri: dan fe

Castalia, 2009, pp. 500-506 (p. 504)]. No es casualidad que las tres, como indica el estema de Guillermo Serés, desciendan de la de Matías Mares. Por un lado, lo aclararían los orígenes flamencos del tipógrafo, como reconoce la mayor parte de la crítica, excepción hecha de Antonio Odriozola, op. cit., p. 8, quien, por los muchos indicios que apuntan a Lyon, lo considera de esa sede; por el otro, las relaciones comerciales con diferentes libreros franceses, tanto de Lyon como de París: Landry y Ruelle son la respectiva demostración. Consolidados sus orígenes, es probable que Mares aprendiera el arte tipográfico en el taller de Cristóbal Plantino, impresor francés asentado en Amberes (Juan Uruñuela, Catálogo de la Exposición Temática de Libros Vascos Antiguos, raros y curiosos, Bilbao, Sociedad Bilbaína, 1989, p. 14, Milagros Ronco, op. cit., p. 359, y Óscar Alonso Álvarez, op. cit., p. 39). Tampoco descarto la circulación en su lugar de origen y, sobre todo en la tipografía en la que se formó, del Examen de ingenios de Huarte de San Juan.

65 Leonardo Coppola, "La proyección de Straparola", pp. 79-80.

66 Jean-Michel Laspéras, op. cit., p. 38.

67 Giovan Francesco Straparola, op. cit. 
de ello las financiaciones de El Patrañuelo y Le Piacevoli notti. Además de la difusión en la Península de la traducción de Straparola, es probable que Ruelle también quisiera favorecer la circulación del texto en Francia, ofreciendo una versión castellana —además de las galas y transalpinas que entonces ya circulaban - a los españoles asentados en Bretaña ${ }^{68}$. La distribución en Francia del Honesto y agradable entretenimiento viene confirmada por la conservación en la Bibliothèque Municipale de Senlis $\left(3895 / 12^{\circ}\right)$ de un ejemplar de la edición de Bilbao $(1580)^{69}$. Se trata, en realidad, de un librito en $12^{\circ}$ que sigue la costumbre de Ruelle de utilizar formatos en $16^{\circ} \mathrm{u}$ otros tamaños de bolsillo. En este sentido, aventuro que en el mercado espańol se ofreciera en $8^{\circ}$, mientras que en Francia, que prefería los volúmenes reducidos, se optó por uno menor.

Espero haber avalado prácticamente todo lo propuesto en el estudio editorial de Reyes Gómez, para quien "los libreros más relevantes de las localidades pueden ser los propios autores o los impresores"70. A fin de guiar al lector por los secretos más recónditos de las oficinas tipográficas y los anaqueles de los costeadores foráneos asentados en la España áurea,

68 Fruto del comercio entre Nantes y las ciudades espańolas, en particular Bilbao, hacia la primera mitad del siglo XVI los españoles fundaron colonias en las principales villas de la Bretaña, entre las cuales destaca Nantes, cuya presencia hizo que "l'idiome castillan a conquis droit de cité dans la ville" (Jules Mathorez, "Notes sur les rapports de Nantes avec l'Espagne (suite)", Bulletin Hispanique, 14, 4 (1912), pp. 383-407, p. 388). Mares, que probablemente descubrió la ferviente emigración hacia estas zonas cuando estaba en las dependencias de Francisco de la Presa, tomó conciencia del hecho de que estos hubieran podido leer en su lengua madre lo que circulaba en francés o italiano. Además, en los años 1566-67 el mismo Francisco de la Presa aparece junto a los hermanos Ruiz entre los negociadores que se ocupaban del comercio de libros entre Nantes - foco que recogía libros procedentes de Lyon, París, Thiers y hacía de puente con la ciudad vasca - y Bilbao ( $C f$. Jules Mathorez, "Notes sur les rapports de Nantes avec l'Espagne (suite et fin)", Bulletin Hispanique, 15, 2 (1913), pp. 188-206 (p. 194); y Paul Jeulin, "Une page de l'histoire du commerce nantais du XVIe siècle au début du XVIIIe siècle”, Annales de Bretagne, 40 (1932), pp. 284-331 (p. 299)).

69 El ejemplar ha sido referenciado también por Marco Federici (Edizione di Francisco Truchado, "Honesto y agradable entretenimiento de damas y galanes"(1569-1612), Tesi di Dottorato di Ricerca, Università degli studi di Roma "La Sapienza", 3 vols, 2011, I, p. 88).

70 Fermín de los Reyes Gómez, "La estructura formal del libro antiguo español", Paratesto, 7 (2010), pp. 9-59 (p. 23). 
parece más que evidente que el mercado francés abrió la puerta para la entrada de los novellieri en España. El análisis del comercio de estos libros indicaría la ruta europea de la novella: primer descanso en Francia, donde a menudo se realizaban traducciones previas, las mismas que luego irían rumbo a Iberia ${ }^{71}$. El caso más vistoso lo representa Bandello. Sus Novelle se tradujeron al español de la paráfrasis francesa de Pierre Boaistuau y François de Belleforest, cuyas Histoires trágiques (París, 1559) ${ }^{72}$ se anticiparon treinta años a la versión castellana ${ }^{73}$. En paralelo al éxito que el maestro piamontés tuvo en Francia, la tradición italiana siguió viva con otros novellieri vertidos antes al francés y solo posteriormente al castellano: verbigracia, Le Piacevoli notti, cuya edición zaragozana (1578) —o cualquier otra anterior perdida ${ }^{74}$ — vino precedida por la lionesa de 1560; Les heures de recréation (París, Ruelle, 1571), de Ludovico Guicciardini, previas a las Horas de recreación, impresas por Matías Mares (Bilbao, 1586); y Les cent nouvelles de J. B. Giraldi mises en française (París, Abel L'Angelier, 1583 $)^{75}$, traducidas por Gabriel Chappuys, que sirvieron de avanzadilla para la Primera parte de las cien novelas (Toledo, 1590) ${ }^{76}$.

71 Cf. Jean-Michel Laspéras, op. cit., pp. 31-48. Sobre esta ruta europea de la novella, remitimos a María Soledad Arredondo, "Frontières et bibliothèques pour les Novelas du Siècle d'Or: Italie, France, Espagne en Gilles Bertrand, Anne Cayuela, Christian Del Vento, Raphaële Mouren (dir.), Bibliothèques et lecteurs dans l'Europe moderne (XVIIe-XVIIIe siècles), Genève, Droz, 2016, pp. 139-155.

72 René Sturel, Bandello en France au XVIe siècle, Bordeaux, Feret, 1918, p. 2, n. 3.

73 A propósito de Bandello en la tradición castellana, véanse sobre todo María Soledad Arredondo, "Notas sobre la traducción en el Siglo de Oro: Bandello francoespañol", en Imágenes de Francia en las letras hispánicas, ed. Francisco Lafarga, Barcelona, PPU, 1989, pp. 217-22, y Guillermo Carrascón, “Apuntes para un estudio” y "Oneste o ejemplares".

74 Cf. Leonardo Coppola, "La proyección de Straparola" y Giovan Francesco Straparola", pp. 62-69.

75 Louise Berthé Besaucéle, J. B. Giraldi. L'Étude sur l'évolution des théories littéraires en Italie au XVI siécle, París, Auguste Picard, 1920, p. 261.

76 Sobre Guicciardini remitimos a David González Ramírez e Ilaria Resta, "Traducción y reescritura en el Siglo de Oro: L'ore di recreazzione de Ludovico Guicciardini en España”, en Los viajes de Pampinea: novella y novela española en los Siglos de Oro, eds. Isabel Colón Calderón, David Caro Bragado, Clara Marías Martínez, Alberto Rodríguez de Ramos, Madrid, SIAL, 2013, pp. 61-76. Acerca de la presencia y difusión en España de los Hecatommithi se remite, en cambio, a Mireia Aldomá García, "Los 
Observamos cómo el éxito editorial galo pudo llevar a los editores relacionados con España a invertir también en su mercado. En buena lógica, las traducciones castellanas resultaron financiadas por franceses que contaban con experiencia dentro del mismo género ${ }^{77}$. Es el caso, como hemos analizado, del parisino Ruelle, que costeó numerosas paráfrasis del italiano, y de los dos Millis, miembros de una familia de impresores, libreros y traductores con negocios en Lyon. A este propósito destacan Les heures de recréation, publicadas sucesivamente en la oficina de Mares por Juan de Millis, y Las Historias trágicas, traducción del francés al castellano por Vicente de Millis y supuestamente financiada por su hermano Juan.

Personalidades afiliadas al mundo francés como los citados Ibarra, Mares, Ruelle y los Millis pertenecen, por tanto, a esa categoría a la que remitía Menéndez Pelayo acerca del éxito de la novella en España, subrayando cómo fueron los "tipógrafos o editores versados en el comercio de libros y en relaciones frecuentes con sus colegas (a las veces parientes) de Italia y Francia los que introducían entre nosotros estas novedades de amena literatura"78.

Los Millis y Jean Ruelle representan el ejemplo de lo antes expuesto. Ambos invierten en el triunfante modelo italiano, compartiendo, además, el mismo taller de Mares, que, como se ha visto, no despreciaba el género narrativo italiano. Acerca del libro de Straparola, González Ramírez cree que el discurso de Menéndez Pelayo valdría para Juan Millis. A su juicio, "difícilmente podremos sostener que la obra de Straparola se tradujo por incentivos [...] de los editores", porque Truchado, para obtener provecho, "debió de seguir interviniendo de una u otra forma en las negociaciones con sus editores"79. Acaso ese discurso podría aplicarse,

Hecatommithi de Giraldi Cinzio en España”, en Studia Aurea: actas del III Congreso de la AISO, III, eds. Ignacio Arellano, Carmen Pinillos, Marc Vitse y Frederic Serralta, Griso/Lemso, Navarra/Toulouse, 1996, pp. 15-22; y La recepción de la "novella" en España: los Hecatommithi de Giraldi Cinzio, Bellaterra, Universitat Autònoma de Barcelona, 1998; y a Marcial Rubio Árquez, "Lucas Gaitán de Vozmediano".

77 Sobre las financiaciones por parte de editores y libreros, véase Anne Cayuela, $L e$ paratexte au Siècle d'or: prose romanesque, livres et lecteurs en Espagne au XVIIe siècle, Genève, Droz, 1996, pp. 59-66.

78 Marcelino Menéndez Pelayo, Orígenes de la novela, Madrid, CSIC, 1962, III, pp. 41-44.

79 David González Ramírez, “En el origen”, p. 1236. 
según creemos, a la segunda parte del texto: por haberse excluido de la cesión de venta (7 de abril de 1576) del traductor a los libreros, esta se podía gestionar a solas ${ }^{80}$. En cambio, resulta innegable la importancia de los libreros en una primera fase de divulgación de la primera parte. Lo admitirá después el mismo González Ramírez cuando desanda lo andado, pues Ibarra, Díaz y García - los editores de la reedición granadina (1582) _ “también requieren un pequeño lugar destacado en este escenario por su decidida apuesta por un autor que, aunque venía avalado por su éxito en Italia y en otros países europeos a cuyas lenguas había sido traducido, repristinaba un modelo narrativo recientemente censurado [el Decamerón]" 81 .

Entonces, quien gestionó los derechos de venta fueron los libreros granadinos que, tal vez animados por René Rabut —impresor francés de la edición de 1582 — negociaron la publicación con Ibarra, y este, a su vez, con Ruelle ${ }^{82}$. El éxito alcanzado con la primera parte, detrás del inicial interés de los editores extranjeros, no permite dudas sobre el hecho de que fueron ellos mismos quienes creyeron a pies juntillas en ese modelo e insistieron en su publicación.

La importancia de los libreros aflora también en la introducción de las novelle en la Espańa de mediados del siglo XVI. La figura que pudo favorecer su importación castellana es el mismo editor de la traducción-estreno de Le Piacevoli notti: nos referimos al de la primera edición francesa (1560): Guillaume Rouillé, también conocido como Rouille, Rovillé, Roviglio o, en su antropónimo latino, Rovillum. Rouillé (1518-1589) empezó de aprendiz en el taller veneciano de Giolito — quien, además, fue el mismo tipógrafo que dio a la estampa las ediciones italianas de Le Piacevoli notti-, convirtiéndose en 1560 en un afamado impresor-editor. A su llegada a Lyon (ca. 1543), entraría en contacto con los Portonarii, se casaría con la hija de Domenico, originario de Trino, y después del traslado de los cuñados a Salamanca, los reemplazó al frente de la actividad editorial ${ }^{83}$.

80 Cf. Leonardo Coppola, "La proyección de Straparola".

81 David González Ramírez, "La princeps", p. 526.

82 Leonardo Coppola, "La proyección de Straparola”, p. 76.

83 Sobre Guillaume Rouillé véase Ilaria Andreoli, "La storia in soldoni: il Promptuaire des medailles di Guillaume Rouille’", en Storia per parole e per immagini, eds. Ugo Rozzo e Mino Gabriele, Udine, Forum, pp. 235-266. 
Entre sus ediciones se registran traducciones al francés y ediciones italianas previas a Le Piacevoli notti ( $1^{\text {a }}$ parte, Lyon, 1560). Destacan, entre otras, $I l$ Cortigiano (Lyon, 1553), Il Decameron (Lyon, 1555) y el Orlando furioso (Lyon, 1556) ${ }^{84}$. Rouillé se amistó con impresores de Lyon, París, Venecia y varias ciudades españolas, convirtiéndose en máximo exponente de los intercambios con España ${ }^{85}$. De acuerdo con los contactos con el mundo del libro español y las negociaciones entre Lyon y Medina, creemos que debió de ser él quien favoreció la difusión en España del texto italiano de Straparola y de su traducción francesa ${ }^{86}$. Medina, canal de veras clave para la compraventa de libros, era el destino de muchos libreros, sobre todo extranjeros ${ }^{87}$. Tipógrafos y editores como los Millis, Giunti, Portonarii y Rouillé desplegaban, gracias a la mediación de fieles "heraldos" asentados en varias urbes, verdaderas redes comerciales que pasaban siempre por la capital del libro medinense $\mathrm{e}^{88}$.

En una serie de actos legales de la familia Giunti, activos en las ciudades de Venecia, Lyon y Medina, se señala la presencia de Rouillé ${ }^{89}$. Este, además de coordinarse, como ya avanzamos, con los Portonarii en Salamanca y Zaragoza, también negociaba con la familia Trechsel. Los herma-

84 Emile Picot, Les Francais italianisants aux XVI siècle, I, Paris, Paris H. Champion, 1906, pp. 200-203.

85 Charles Péligry, op. cit., p. 87.

86 Un ejemplar de su edición se registra en la biblioteca Menéndez y Pelayo de Santander (R-IV-1-6). Como indica el CCPBE [http://www.mcu.es/bibliotecas/MC/ $\mathrm{CCPB} /$ index.html], fue publicado con la traducción de las Facetie, motti et burle, de Lodovico Domenichi, costeado por el mismo Rouillé con el título de Facecies, et mots subtilz, d'aucuns excellens expritz et tresnobles seigneurs. En Francois, et Italien (Lyon, Robert Granjon, 1559).

87 Anastasio Rojo Vega, op. cit., p. 22, calcula más de 140 libreros en la Medina del siglo XVI, la mayoría de los cuales eran de Lyon o Thiers.

88 La familia Giunti —impresores del Decameron ricorretto-, además de fortalecer sus lazos con Lyon, también tenía representantes familiares en Salamanca, Burgos, Zaragoza y Madrid. Vincenzo y Simone Portonarii se mudaron, por ejemplo, de la ciudad gala a Salamanca, frecuentando entre tanto a la industria de Lyon a través del cuñado Rouillé (Charles Péligry, op. cit., p. 87). En cuanto a los Millis, Guillermo, luego de asentarse en Medina, hizo de representante del familiar lionés y también editor Vicencio Millis (Anastasio Rojo Vega, "El negocio del libro", p. 20).

89 Cristóbal Pérez Pastor, La imprenta en Medina del Campo, Madrid, Establecimiento tipográfico "Sucesores de Rivadeneyra", 1895, pp. 419-502. 
nos Melchor y Gaspar Trechsel se instalaron respectivamente en Alcalá y Medina ${ }^{90}$. Y después de la muerte de Gaspar (1571), Melchor gestionaría también la librería medinense del editor lionés. Las noticias ofrecidas por Rojo Vega, luego retomadas por Cátedra ${ }^{91}$, nos facultan para concluir que el inventario de la sucursal de Medina, redactado a la muerte de Gaspar, evidenciaba una intensa actividad comercial también con Baeza. En efecto, bajo la voz "Baeza” se registran las deudas que los Montoya y los Vega contrajeron con el representante de Rouillé. A este propósito se dice: "debe Juan Bautista [de Montoya] y su mujer vecino de Baeza por obligación treinta mil maravedís". Asimismo, se añade que "debe Juan de Vega librero vecino de Baeza veinte y dos reales que le emprestó Melchor Trechel en nombre de Gaspar Trechel"92.

Ambas familias se vincularon con las ediciones baezanas de la segunda parte del Honesto y agradable entretenimiento: Montoya como impresor de las ediciones 1581, 1582 y 1583, y Juan de Vega, como indica Cátedra ${ }^{93}$, en calidad de padre de Antonio de Vega, librero de la primera edición jiennense $(1581)^{94}$.

A estas alturas, y atendiendo a la historia del comercio de libros, creemos que el texto original de Straparola llegó a Medina del Campo, donde confluían la mayoría de los libreros de Baeza y Granada, y donde pudo negociarse el envío desde Venecia, sede de la princeps de las dos partes de Le Piacevoli notti.

Examinando a fondo las informaciones de Rojo Vega, Gaspar Trechsel, el intermediario de Guillaume Rouillé, quizá tratara del envío del texto italiano con Montoya o con la familia de los libreros baezanos De Vega.

90 Informaciones sobre los negocios entre las familias y agentes de Rouillé se hallan en Jean-Michel Laspéras, op. cit., p. 46, n. 65.

91 Pedro María Cátedra, Imprenta y Lecturas en la Baeza del siglo XVI, Salamanca, Seminario de Estudios Medievales y Renacentistas, 2001, pp. 59 y 61.

92 Las noticias se han tomado del artículo "Guillaume Rouillé: Inventario de su tienda de Medina del Campo (1571)”, consultable en la sección Artículos de la web de Anastasio Rojo Vega: http://anastasiorojovega.com/.

93 Pedro María Cátedra, op. cit., pp. 61-62.

94 Nos referimos solo al estado A, patente en la Biblioteca Jagellona de Cracovia (CIM.O.809) (Cfr. Pedro María Cátedra, op. cit., pp. 223-225), porque las siguientes ediciones saldrán sin promotor. A éste propósito véase Leonardo Coppola, "Proyección de Straparola”, p. 81. 
De todas formas, me inclino a pensar que el texto llegó a Castilla por recomendación de Rouillé, que tenía contactos con los Giunti de Venecia. Una vez adquirido, Rouillé pudo despacharlo a Gaspar Trechsel, muy próximo a los libreros de Jaén; los mismos que luego se lo procuraron a Truchado, quien, como teoriza Baranda ${ }^{95}$, durante aquellos años, y junto con Antonio de Benavides, formaba en Baeza un círculo de traductores de textos italianos.

Tampoco excluyo la hipótesis de que fueran los granadinos Juan Díaz y Francisco García los primeros en entrar en contacto con el texto remitido luego a Truchado. En este caso representarían a la categoría de libreros de la época que, siempre atentos al mercado, detectaron en Le Piacevoli notti la "apetencia que [...] sentían por esta clase de [volúmenes] de pasatiempo, [...], que, a la postre, adivinando la brava y rica mina que las novelas italianas contenían y las pingües ganancias [...] brindaban a quienes las tradujesen en castellano" 96 . Cabe señalar, por último, su dinámica red comercial con vendedores extranjeros. En los ańos 1564-1571 colaboraron sobre todo con Medina del Campo y Pierre Landry, con el que ampliaron las compraventas también en 1582 y $1583^{97}$. Asimismo, quizá impelidos por el francés René Rabut, que trabajaba con los editores granadinos y sabía del éxito de Le Piacevoli notti en Francia ${ }^{98}$, y tras haber encontra-

95 Nieves Baranda, "Literatura en sociedad. Dos tratados italianos de saber vivir en la Andalucía de la Contrarreforma", en Spagna e Italia attraverso la letteratura del secondo Cinquecento, eds. Encarnación Sánchez García, et al., Napoli, Istituto Universitario Orientale (Dipartimento di Studi Letterari e Linguistici dell'Orientale), Collana di Letterature Comparate, 2, 2001, pp. 301-320 (p. 314).

96 Agustín González de Amezúa, Cervantes, creador de la novela corta española, Madrid, CSIC, 1982, pp. 446-447.

97 Juan María de la Obra Sierra, María José Pérez Osorio y Amparo Moreno Trujillio, "El mercado del libro en Granada en el siglo XVI", en La imprenta en Granada, eds. Cristina Peregrín Pardo et al., Granada, Universidad de Granada y Consejería de Cultura de la Junta de Andalucía, 1997, pp. $44-71$ (p. 58); y Juan María de la Obra Sierra, "El libro jurídico en la librería de Francisco García (Granada 1583-1601)", en Libros y documentos en la Alta Edad Media. Los libros de derecho. Los archivos familiares, II, ed. Carlos Sáez Sánchez, Madrid, Calambur, 2002, pp. 311-343 (p. 313).

98 Según Alfredo Vílchez Díaz, "Primeros pasos: el siglo XVI", en La imprenta en Granada, ed. Cristina Peregrín Pardo, Granada, Universidad de Granada / Junta de Andalucía / Consejería de Cultura, 1997, pp. 21-42 (pp. 34-37), el francés René Rabut, que no sabe ni leer ni escribir, se asienta en Granada desde 1534, estable- 
do quien lo tradujera (Truchado), no descarto que a ellos se le deba la importación del libro a España y la compra a Truchado en 1576 de los derechos de venta99. La entrada de libros foráneos está bien documentada en Granada desde los primeros tiempos de la imprenta, sin orillar que las bibliotecas particulares de algunos prelados dan fe de ello ${ }^{100}$.

A tenor de los contactos de Rouillé con Venecia y la ruta comercial de los libros del tiempo de los Austrias, la edición italiana que sirvió de base a la traducción — probablemente la de $1565^{101}$ — acaso llegó directamente desde Lyon. Debido a los muy parcos negocios en el Adriático, los textos venecianos desembocaban en Lyon y luego en Nantes ${ }^{102}$, que hacía de puente en el intercambio entre Venecia y Bilbao ${ }^{103}$. Por consiguiente, de la capital vasca los bienes se enviaban a Medina o, por vía marítima y a través de la mediación de Medina, a Sevilla ${ }^{104}$. Como reconoce Laspéras, la ruta Bilbao-Medina contribuyó al desarrollo de la tipografía hispana y a la impresión de diversas traducciones de novelle y facecias, gracias a la presencia en la Península de impresores extranjeros como Matías Mares (Bilbao), Guillén de Brocar (Logroño), Thomas Porralis (Pamplona) y Adrián de Amberes (Estella) ${ }^{105}$.

ciendo contactos con libreros del lugar como Juan Díaz y Francisco García. Noticias más detalladas sobre el impresor galo y su taller andaluz pueden hallarse en Juan Martínez Ruiz, "Visita a las imprentas granadinas de Antonio de Nebrija, Hugo de Mena y René Rabut en el ańo 1573", Revista de dialectología y tradiciones populares, 24 (1968), pp. 75-110 (pp. 79-95).

99 También por esta razón se continuaría teorizando sobre la existencia de una edición perdida, en este caso granadina, anterior a la zaragozana de 1578. Esta cuestión ha sido estudiada en Leonardo Coppola, "La proyección de Straparola” y avalada desde la ladera ecdótica en nuestra edición (Giovan Francesco Straparola, op. cit.).

100 Juan Martínez Ruiz, op. cit., pp. 89-90.

101 Sobre este asunto remitimos a Doris Senn, op. cit., p. 56; Marco Federici, Edizione di Francisco, I, pp. 127-129, Francisco Truchado, op. cit., pp. 82-87; y Giovan Francesco Straparola, op. cit. Un ejemplar de la versión italiana (1565) se conserva en Paris, Bibliothèque nationale (Y2-10763).

102 Felipe Ruiz Martin, Lettres marchandes échangées entre Florence et Medina del Campo, Paris, S.E.V.P.E.N, 1965, p. 15.

103 Jules Mathorez, "Notes sur les rapports de Nantes avec l'Espagne (suite et fin)", p. 193.

104 Anastasio Rojo Vega, "El negocio del libro", p. 22.

105 Jean-Michel Laspéras, op. cit., p. 42. 
Pese a la presencia de impresores foráneos en el norte del país, el impulso en la difusión de los novellieri surgió principalmente de los libreros, puesto que personalidades francesas como los citados Trechsel, Landry y Rouillé, asiduos en las tiendas de Lyon, París, Venecia y las ciudades españolas, favorecieron la introducción de Straparola en el Imperio de Felipe II. Luego si el parisino Rouillé contribuyó a la importación del texto italiano a España, su compatricio Ruelle permitió la realización de la edición bilbaína tras la del champenois Ibarra.

En último término, cabe señalar algunas coincidencias francesas en el texto de la paráfrasis española, empezando porque, como en el caso de la gala, en la piel de toro se publica solo la primera parte. El segundo libro "solo" salió por primera vez en 1581, es decir, una vez consolidado el éxito editorial del primero ${ }^{106}$.

Ausente en el original italiano, el texto castellano, igual que el francés, se abre con una tópica dedicatoria. La versión gala se ofrece a un tal François Rogier, consejero real, tesorero de Francia y protector militar que, cansado de sus misiones bélicas, podría recrearse con su lectura entretenida ${ }^{107}$. Rouillé, "induit par leur exemple"108, presenta la colección como un "plasir e contentemente d'esprit", pues se trata de un libro de "recreation agreable"109. La misma obertura de Truchado parece tener rasgos comunes con la francesa, que, quizás, pudo servirle de guía. En su dedicatoria, el baezano caracteriza la obra como un "agradable entretenimiento" por "sus morales y virtuosas flores" 110 . Tanto la presentación del libro en el épître de Rouillé como el título de otro texto de la tradición francesa, que indicaremos en seguida, son síntomas que pudieron dejarse sentir sobre Truchado a la hora de adoptar el título con el que hoy se conoce la versión española de Straparola.

En la tradición gala existe una colección anónima de unas cincuenta novelas de inspiración boccacciana contadas por aristócratas reunidos en un consistorio: la famosa cornice dominada por el prodesse et delectare

106 Leonardo Coppola, "Proyección de Straparola".

107 Ruth Bottigheimer, op. cit., p. 23.

108 Jean François Straparole, Les Facecieuses Nuictz, trad. J. Louveau, Guillaume Rouille, Lyon, 1560, f. 3v.

109 Ibidem, f. $4 \mathrm{v}$.

110 Giovan Francesco Straparola, op. cit. pp. 93-94. 
horaciano ${ }^{111}$. Me refiero al Parangon des nouvelles honnestes et délectables (Lyon, Morin, 1531) ${ }^{112}$, cuyo título pudo servir de piedra de toque al traductor andaluz. Salta a la vista el probable calco (Honesto y agradable), tomado quizá del idéntico "honnestes et delectables" del Parangon.

Al mismo tiempo, el anónimo Parangon —o sea, "modelo"-, parece haber inaugurado en Francia un género destinado al público femenino. Como subrayó Sozzi ${ }^{113}$, también Bonaventure des Périers, en sus Les Nouvelles récréations et joyeux devis (Lyon, 1558) —reeditadas, entre otras cosas, por Rouillé en $1561^{114}$ _, enderezó sus novelle a las mujeres. Lo mismo se distingue en el caso del citado Jacques d'Yver, quien en Le Printemps dedica su colección de nouvelles "aux belles et vertueuses demaiselles" 115 . Se trata, pues, como testimonian los paratextos que Truchado dedicó a Isabel Ana de Carvajal y Leonor Carrillo de Quesada, del mismo tipo de lectoras.

La conexión con el ambiente francés, "patrocinador" del texto italiano a través de su envío a Espańa por Rouillé y la actividad promotora asumida por los diferentes impresores y libreros galos, certifica la importancia que aquellos tuvieron en la fortuna de Le Piacevoli notti, primero valorada en Francia y luego trasladada a Espańa con su traducción. Los libreros y editores del país vecino favorecieron la introducción de Straparola y reabrieron el comercio de los novellieri, primero en la Espańa septentrional (Bilbao, Zaragoza y Pamplona), a resultas de las cercanías con Francia — que ya había apreciado el género- - Sucesivamente, siempre detrás de figuras francesas - René Rabut por lo que atañe al Honesto y agradable entretenimiento-, también el mercado meridional hizo suyos a los novellieri, esta vez por mor de libreros peninsulares (Díaz y García), que, como los franceses, aunque más tarde, descubrieron el provecho que estos textos, despojados de su carácter licencioso o desenvuelto, aportaban al panorama español de las postrimerías del Renacimiento y los albores del Barroco ${ }^{116}$.

111 Gabriel Pérouse, Le Parangon des nouvelles, Genève, Droz, 1979.

112 Un ejemplar de la reedición de 1532 se conserva en la Biblioteca Capitular y Colombina de Sevilla (Sign. top.: 3-2-2).

113 Lionello Sozzi, Boccaccio in Francia nel Cinquecento, Genève, Slatkine, 1971, p. 76. 114 Bénédicte Boudou y Jean-Claude Arnould, "Bibliographie d'Agrégation 20082009: Bonaventure des Périers, Nouvelles récréations et joyeux devis”, Seizième Siècle, 5(2009), pp. 319-341.

115 Paul Lacroix, Les vieux conteurs francais, Genève, Slatkine, 1970, p. 519.

116 Sobre el panorama meridional de la traducción de Truchado y su posterior difusión 


\section{ApÉNDICE}

\begin{tabular}{|c|c|c|}
\hline & IMPRESOR & EdITOR \\
\hline Zaragoza, 1578 & Juan Soler & $\begin{array}{c}\text { Pedro de Ibarra / Pierre } \\
\text { Collet }\end{array}$ \\
\hline Bilbao, 1580 & Matías Mares & Juan Ruelle / Jean Ruellé \\
\hline $\begin{array}{l}\text { Granada, } \\
1582 / 83\end{array}$ & René Rabut & $\begin{array}{c}\text { Juan Díaz y Francisco } \\
\text { García }^{117}\end{array}$ \\
\hline Madrid, 1598 & Luis Sánchez & Miguel Martínez \\
\hline \multirow[t]{3}{*}{ Pamplona, 1612} & Nicolás de Assiayn & Nicolás de Assiayn \\
\hline & II & \\
\hline & IMPRESOR & EdITOR \\
\hline Baeza, 1581 & Juan Bautista de Montoya & Antonio de Vega ${ }^{118}$ \\
\hline Baeza, 1582 & Juan Bautista de Montoya & - \\
\hline Baeza, 1583 & Juan Bautista de Montoya & - \\
\hline Madrid, 1598 & Luis Sánchez & Miguel Martínez \\
\hline Pamplona, 1612 & Nicolás de Assiayn & Nicolás de Assiayn \\
\hline
\end{tabular}

americana remitimos a Leonardo Coppola, "Mercado librario y mundo editorial en las ediciones andaluzas del Honesto y agradable entretenimiento de damas y galanes: inventarios y exportación al Nuevo Mundo", Etiópicas, 13 (2017), pp. 117-138.

117 Como ya se argumentó en Leonardo Coppola, "La proyección de Straparola", pp. 80-81, la presencia de dos libreros en la portada de la primera parte granadina nos llevaría a hablar de una coedición formada con las segundas partes (1582 y 1583). Más detalles sobre este asunto pueden leerse en Leonardo Coppola, "Mercado librario". 118 Solo aparece en el estado A poseído por la Biblioteca Jagellona de Cracovia. 